\title{
Contributions
}

Zhiyong Yao* and Wen Zhou

\section{Vertical or Horizontal: Endogenous Merger Waves in Vertically Related Industries}

\begin{abstract}
Endogenous merger waves are studied in vertically related industries where firms may engage in both vertical and horizontal mergers. It is shown that whether and how firms merge depends crucially on the balance between vertical and horizontal externalities, and the balance between upstream and downstream competition. Furthermore, firms may merge with or without any fundamental change in the underlying economic conditions.
\end{abstract}

Keywords: merger waves, endogenous mergers, vertical mergers, horizontal mergers, stable market structure

JEL Code: L1, L2, D4

DOI 10.1515/bejeap-2014-0165

\section{Introduction}

It has been well documented that mergers occur in waves, clustering in time and by industry (e.g. Andrade, Mitchell, and Stafford 2001; Mitchell and Mulherin 1996). Some merger waves are horizontal, consisting mainly of mergers between competing firms in the same industry, while some others are vertical, made up mainly of mergers between suppliers and customers. For example, the first great merger wave in the United States (1890s-1904) was horizontal. Consolidation between competitors generated corporate giants in the steel, telephone, oil, mining, railroad, and other major manufacturing and service industries. The second great merger wave (1910s-1929), by contrast, was mainly vertical. Ford and General Motors emerged as the major automobile manufacturers through vertical integration, acquiring every business along the supply chain from iron and coal mining to railroads and water transportation, steel mills, all the way to

*Corresponding author: Zhiyong Yao, School of Management, Fudan University, Room 236, Siyuan Building, 670 Guoshun Road, Shanghai 200433, China, E-mail: yzy@fudan.edu.cn Wen Zhou, Faculty of Business and Economics, The University of Hong Kong, Pokfulam Road, Hong Kong, China, E-mail: wzhou@business.hku.hk 
finished vehicles (Lipton 2006; Martynova and Renneboog 2008). In the United States, the cement and ready-mixed concrete industries underwent at least two waves of vertical integration in the 1960s and 1980s (Hortacsu and Syverson 2007).

Horizontal mergers may cluster not only in a single industry, but also across several industries that are vertically related. For example, a series of mergers in the US pharmaceutical industry occurred in 2007 to counteract the increased bargaining power in the downstream health care industry, where consolidation had been taking place. ${ }^{1}$ Furthermore, a wave of integration along one dimension may follow a wave of disintegration along another. In other words, the market may switch between vertical and horizontal integrations. Semiconductor companies used to be vertically integrated. With rising costs and a changing cost structure, economies of scale became more important, and firms started to disintegrate vertically and merge horizontally. ${ }^{2}$

These examples highlight the need to study horizontal and vertical mergers together, as a merger will alter the incentives for other mergers, and the impacts are likely to be different depending on whether the mergers are vertical or horizontal. Given the observed regularity of horizontal and vertical merger waves, the following questions immediately emerge: What causes firms to merge in vertically related industries? Why do they merge in waves? And what determines whether a wave is vertical or horizontal? There have been some economic studies on horizontal merger waves (in a single industry) and a few on vertical merger waves, but virtually none in which the two are considered together. This research studied mergers in vertically related industries and is therefore well positioned to address the last question. In doing so, the analysis has shed new light on the answers to the first two questions.

Consider two vertically related industries, each consisting of two firms that may engage in both horizontal and vertical mergers. ${ }^{3}$ Mergers must be endogenous, i.e. the market structure shifts from a stable configuration in which no firm is merged to another in which many firms are merged. The analysis shows that a market structure is stable only when no firm merges or all firms merge, so mergers always occur in waves. Depending on whether the stability conditions for the two structures coincide, a merger wave may be triggered in two ways. Market structure may change because the underlying conditions have changed, or firms switch between stable structures without any change in the

1 "Meandering giants," The Economist, March 24, 2007.

2 "Under new management," The Economist, April 2, 2009.

3 Since each industry has only two firms, a horizontal merger "wave" in this context would be horizontal mergers in both industries, which is slightly different from the usual meaning of multiple mergers in a single industry. 
fundamentals. The first case corresponds, for example, to an economic shock that changes the cost, demand, or regulatory situation, so the trigger is tangible. In the second case, the trigger may be intangible, corresponding to something trivial or totally unrelated to the underlying economic conditions, such as rumors or changes in mood or expectations.

The main contribution of this study is to link the two triggers to demand and cost properties, and to identify the conditions determining whether a merger wave is horizontal or vertical. We find that the stability of market structure depends crucially on the relative intensity between vertical and horizontal externalities, and the relative intensity of upstream and downstream competition. Vertical mergers eliminate vertical externalities (double markup) but intensify horizontal externalities (competition in the downstream industry). Horizontal mergers lessen horizontal externalities in both industries but exacerbate vertical externalities. If the two externalities are balanced, one will mitigate the other as long as all four firms remain independent. This explains why firms may refrain from merging, a necessary component for the endogenization of merger waves. If the balance is disrupted, i.e. if the externalities become more severe along either dimension, firms will start to merge. For example, when the demand for the final product becomes more convex, double markup will be more damaging, which strengthens the incentive for vertical integration.

While the externalities mainly affect the four firms' total profits, the relative intensity of competition in the two industries affects how the total profits are distributed among them. When competition in the two industries is balanced, firms tend to remain independent or merge vertically. When the balance is disrupted, firms will merge horizontally. For example, when the final products become closer substitutes, horizontal competition is intensified and firms merge horizontally in both industries. So competition in one industry may induce mergers in a vertically related industry. Not merging and vertical mergers tend to share the same conditions while horizontal mergers correspond to different conditions, so vertical merger waves are more likely to be associated with intangible triggers, while a horizontal merger wave tends to be associated with a tangible trigger.

Research has long established that mergers tend to occur in waves, and scholars have usually explained the waves in terms of economic shocks at the industry or economy level (Andrade, Mitchell, and Stafford 2001; Andrade and Stafford 2004; Harford 2005; Jensen 1993; Jovanovic and Rousseau 2002; Mitchell and Mulherin 1996; Shleifer and Vishny 2003). In the industrial organization literature, there are a few theoretical papers on merger waves, all in a single industry. Nilssen and Sorgard (1998) have analyzed sequential horizontal mergers to demonstrate their temporal interdependence. Fauli-Oller (2000) has 
studied sequential mergers among firms with asymmetric costs, and found that a merger's profitability is affected by both the demand level and mergers among other firms. ${ }^{4}$ Qiu and Zhou (2007) endogenize multiple mergers and attribute merger waves to economic shocks. While these papers focus on the interaction between mergers in a single industry, we are interested in the ultimate causes for mergers in vertically related industries, where the choice between vertical and horizontal mergers becomes a central issue.

Toxvaerd (2008) has shown in a timing game that no-merger and multiple merger may coexist, which implies the possibility of tangible and intangible triggers. Nevertheless, the driving force for the two triggers in our model is very different and, more importantly, we relate the triggers to types of merger waves and specific demand and cost conditions. Colangelo (1995) has studied vertical and horizontal mergers together. He is mainly interested in exclusive, single mergers that are assumed to be substitutes, while this study considers multiple mergers that turn out to be complements. Colangelo's merger decisions are sequential and semi-exogenous, while in this study everything including the merger process is endogenous. Giovannetti (2005) has analyzed a "diagonal" merger, which contains both vertical and horizontal elements, between two Internet Service Providers, and demonstrated the possibility of foreclosure in the market where the merger is horizontal but not in the market where it is vertical. Both our paper and Giovannetti's (2005) study mergers involving vertical and horizontal relations, and both consider product differentiation. While Giovannetti has studied a single exogenous merger in the context of internet service providers with the bottleneck features, we are primarily interested in multiple, endogenous mergers in a more traditional setting with upstream wholesalers and downstream retailers. He has focused on the effect of the merger on foreclosure, while we focus on the stability of market structure.

Greenhut and Ohta (1979) have demonstrated that successive duopolists would both merge vertically, but Bonanno and Vickers (1988) and Lin (1988) have shown that firms may choose vertical disintegration in order to dampen downstream competition. Our model synthesizes these contradictory results, as we show that both market structures can be stable even under the same conditions. Like Greenhut and Ohta (1979), we emphasize the role of double markup in driving vertical mergers. Like Bonanno and Vickers (1988) and Lin (1988), we show that firms may refrain from profitable vertical mergers because vertical disintegration generates a vertical externality that mitigates the horizontal externality associated with horizontal competition. Unlike their setting in

4 Fridolfsson and Stennek (2005) have shown that firms may merge to prevent their partners from merging with a rival. 
which the only alternative to not merging is vertical integration, firms in our model have the additional option of horizontal merger.

\section{Model}

Consider two vertically related industries. The upstream industry consists of two identical firms, $A$ and $B$, and the downstream industry also consists of two identical firms, 1 and 2. A homogeneous input is produced by each upstream firm at cost $C(q)$, where $q$ is the produced quantity. The input is sold through arm's-length transaction to the downstream firms, which then transform it into a final product at zero extra cost on a one-for-one basis. The demand for final product $i$ is $p_{i}\left(q_{i}, q_{j}\right)$, where $i, j \in\{1,2\}$ and $i \neq j$, with $\frac{\partial p_{i}}{\partial q_{i}} \leq \frac{\partial p_{i}}{\partial q_{j}} \leq 0$.

The firms play a two-stage game. In stage 1 , each firm chooses simultaneously a merger partner. A firm can commit to independence by choosing itself as the partner. A merger can be either horizontal (between two downstream firms or two upstream firms) or vertical (between a downstream firm and an upstream firm), and it takes place if and only if two firms choose each other as partners. A merged entity is not allowed to participate in any further mergers. ${ }^{5}$ The merger decisions result in a market configuration, which is publicly announced.

The game then proceeds to stage 2. Given the market configuration from the first stage, all the resulting firms compete to maximize their payoffs. Within a merged entity, the two partners share the merger surplus equally, ${ }^{6}$ where the surplus is calculated assuming a fixed configuration among the other firms. For example, a merger between firms $A$ and 1 in $N \equiv\{A, B ; 1,2\}$ leads to $S \equiv\{B ; A 1,2\}$, so $\pi_{A}^{S}=\pi_{A}^{N}+\frac{1}{2}\left(\pi_{A 1}^{S}-\pi_{A}^{N}-\pi_{1}^{N}\right)$ and $\pi_{1}^{S}=\pi_{1}^{N}+\frac{1}{2}\left(\pi_{A 1}^{S}-\pi_{A}^{N}-\pi_{1}^{N}\right)$, where $A 1$ denotes the entity resulting from a merger between firms $A$ and 1 , and $\pi_{i}^{X}$ is firm $i$ 's payoff in configuration $X$ with $i \in X$.

A configuration is stable if no deviation by any individual firm or pair of firms is profitable. A deviation is profitable if all deviators are better off (strictly for at least one) for any possible configuration among the other firms. Sasaki

5 If firms are allowed to merge multiple times, the final market structure will inevitably be a single monopoly encompassing both industries. The assumption precludes such a trivial and uninteresting case. Besides, merging into monopoly will be prohibited in real life by antitrust authorities.

6 This assumption can be justified by implementing alternating-offer bargaining à la Rubinstein (1982). As will be clear later, what matters for the paper's major conclusion is the participation constraint rather than the sharing rule: A merger usually takes place if and only if the two merging firms' total profits increase; it does not matter how they divide the surplus. 
and Toda (1996) have proved the existence of the equilibrium in the context of one-to-one matching with externalities. ${ }^{7}$ We look for conditions for endogenous merger waves, which are defined as the transition from one stable market structure in which no firm is merged to another in which all firms are merged.

\section{An example}

Because the analyses of stable market structure and the corresponding merger waves are quite involving, it is helpful to first study a more specific setting as an example. Consider the following demand and costs: The marginal cost of producing the input is constant: $C(q)=c q$. The final products are perfect substitutes and the demand for them is linear: $p=\alpha-Q$, where $Q$ is the total quantity produced by the two downstream firms. Firms compete à la Cournot in both industries. Each downstream firm regards the input price, denoted $t$, as given and chooses its output. The downstream Cournot equilibrium will give rise to $Q$ as a function of $t$, which is then inverted to generate the inverse demand for the input, i.e. $t$ as a function of $Q$. Facing this derived demand, the upstream firms engage in their Cournot competition. ${ }^{8}$

The game is solved by backward induction. Suppose that at the beginning of stage 2 the market configuration contains $v$ vertically integrated firms, $u$ independent upstream firms, and $d$ independent downstream firms. Because marginal costs are constant and identical within an industry, a horizontal merger is equivalent to eliminating one of the merging firms. A vertically integrated firm participates only in the downstream competition, ${ }^{9}$ and it differs from an

7 Work on coalition formation with externalities (Bloch 1996; Ray and Vohra 1999) has made use of various equilibrium concepts from cooperative game theory, but those concepts lead to either a very large set of equilibria or an empty set, therefore, are not suitable for the questions studied here. The equilibrium concept adopted here captures the essential interdependence of firms' merger incentives without having to specify details such as the order of moves, which so often will greatly affect the equilibrium outcome. Since a merger involves two firms, collective deviation must be considered, as deviating into a new merger requires two firms to change their strategies simultaneously. Because a merged entity's profits depend on other firms' merger structures, this merger game is essentially a one-to-one matching game with externalities (Roth and Sotomayor 1990; Hafalir 2008).

8 The successive Cournot oligopoly setting has been widely used. See Greenhut and Ohta (1976) and Salinger (1988), for example.

9 Salinger (1988) has pointed out that a vertically integrated entity will withdraw from the upstream competition - it neither buys the input from other upstream firms nor sells it to other downstream firms. Some researchers have raised concerns about commitment power in 
independent downstream firm in that its input is procured at cost $c$ rather than the market price $t$. In the downstream competition, therefore, a vertically integrated firm chooses $q_{v}$ to maximize $\pi_{v} \equiv(\alpha-Q-c) q_{v}$, which leads to the firstorder condition $\alpha-q_{v}-Q=c$. Since $Q=v q_{v}+d q_{d}$ (using symmetry), the firstorder condition can be rewritten as:

$$
\alpha-(v+1) q_{v}-d q_{d}=c .
$$

Likewise, the first-order condition for an independent downstream firm is $\alpha-q_{d}-Q=t$, or

$$
\alpha-(d+1) q_{d}-v q_{v}=t .
$$

These two equations lead to

$$
q_{v}=\frac{\alpha-(d+1) c+d t}{d+v+1} \text { and } q_{d}=\frac{\alpha-(v+1) t+v c}{d+v+1} .
$$

The demand for the input for independent upstream firms is therefore

$$
Q_{i} \equiv d q_{d}=\frac{d[\alpha+v c-(v+1) t]}{d+v+1},
$$

or

$$
t=\frac{\alpha+v c}{v+1}-\frac{d+v+1}{d(v+1)} Q_{i},
$$

where $Q_{i} \equiv d q_{d} \equiv u q_{u}$ is the total quantities produced by the independent upstream or downstream firms. Facing this derived demand, an upstream firm will choose $q_{u}$ to maximize $\pi_{u} \equiv\left[\frac{\alpha+v c}{v+1}-\frac{d+v+1}{d(v+1)} Q_{i}-c\right] q_{u}$. The Cournot equilibrium is then given by

$$
q_{u}=\frac{d(\alpha-c)}{(u+1)(d+v+1)}
$$

Consequently,

$$
\begin{gathered}
q_{d}=\frac{u(\alpha-c)}{(u+1)(d+v+1)}, q_{v}=\frac{[d+(u+1)(v+1)](\alpha-c)}{(u+1)(v+1)(d+v+1)}, \\
\text { and } Q=\frac{[(u+1)(v+1)(d+v)-d](\alpha-c)}{(u+1)(v+1)(d+v+1)} .
\end{gathered}
$$

Salinger's setting, but the issue is not serious in this analysis because firms compete on quantity rather than price (Hart and Tirole 1990; Ordover, Saloner, and Salop 1990). Schrader and Martin (1998) provide further arguments in support of Salinger's conclusion. 
It is clear that all profits are proportional to $(\alpha-c)^{2}$, so we can normalize $\alpha-c \equiv 1$ without losing any generality. The profits of the three types of the firm are then:

$$
\begin{aligned}
& \pi_{v}(v, u, d)=\frac{[d+(u+1)(v+1)]^{2}}{(u+1)^{2}(v+1)^{2}(d+v+1)^{2}}, \\
& \pi_{u}(v, u, d)=\frac{d}{(u+1)^{2}(v+1)(d+v+1)}, \text { and } \\
& \pi_{d}(v, u, d)=\frac{u^{2}}{(u+1)^{2}(d+v+1)^{2}} .
\end{aligned}
$$

Now move back to stage 1 . There are six possible market configurations as listed in Table 1. Firms' payoffs can be calculated using the formulas derived above. For example, in $S_{1} \equiv\{A, B ; 1,2\}, v=0, u=2, d=2$. As specified earlier, each merged entity divides the merger surplus/deficit equally between the two partners.

Table 1: Payoffs in the six configurations. ${ }^{10}$

\begin{tabular}{lllllr}
\hline Configuration & \multicolumn{1}{c}{$\boldsymbol{\pi}_{\boldsymbol{A}}$} & \multicolumn{1}{c}{$\boldsymbol{\pi}_{\boldsymbol{B}}$} & $\boldsymbol{\pi}_{\mathbf{1}}$ & $\boldsymbol{\pi}_{\mathbf{2}}$ & Total profits \\
\hline$S_{1} \equiv\{A, B ; 1,2\}$ & 74 & 74 & 49.4 & 49.4 & 247 \\
$S_{2} \equiv\{A B ; 12\}$ & 62.5 & 62.5 & 31 & 31 & 188 \\
$S_{3} \equiv\{A 1, B 2\}$ & 62.5 & 62.5 & 48.6 & 48.6 & 222 \\
$S_{4} \equiv\{B ; A 1,2\}$ & 99 & 42 & 74.5 & 28 & 243 \\
$S_{5} \equiv\{A B ; 1,2\}$ & 83 & 83 & 28 & 28 & 222 \\
$S_{6} \equiv\{A, B ; 12\}$ & 55.5 & 55.5 & 55.5 & 55.5 & 222 \\
\hline
\end{tabular}

Proposition 1. In the example with constant marginal cost for input production, linear demand for final products that are perfect substitutes, and Cournot competition in both industries, only $S_{1}$ and $S_{3}$ are stable.

Proof: $S_{1}$ is stable. There are three possible deviations, but none of them are profitable: $A+B$ is unprofitable when 1 and 2 merge; $1+2$ is unprofitable when $A$ and $B$ merge; and $A+1$ is unprofitable when $B$ and 2 merge.

10 For ease of comparison, the fractions of the payoffs are multiplied by 1,000 and turned into numerical values. 
$S_{2}$ is not stable because $A+1$ is a profitable deviation: If $B$ and 2 merge, $A+1$ will leave $A$ indifferent but 1 strictly better off; if $B$ and 2 remain independent, both $A$ and 1 are strictly better off.

$S_{3}$ is stable. There are three possible deviations (excluding symmetric ones), but none is profitable: Breaking up $B 2$ is unprofitable when $A$ and 1 remain merged; $A+B$ is unprofitable when 1 and 2 merge; $1+2$ is unprofitable when $A$ and $B$ merge.

$S_{4}$ is not stable because $B+2$ is a profitable deviation (whether $A$ and 1 separate or remain merged).

$S_{5}$ is not stable because $1+2$ is a profitable deviation (whether $A$ and $B$ separate or remain merged).

$S_{6}$ is not stable because $A+B$ is a profitable deviation (whether 1 and 2 separate or remain merged).

Q.E.D.

Proposition 1 says that a stable configuration will have either four independent firms or two vertically merged firms. To understand this conclusion, it is useful to summarize the payoffs in Table 1 into the following three rankings.

R1: An exogenous merger, one fixing the configuration among the remaining two firms, is always profitable. This is because a merger internalizes either the horizontal externality (due to horizontal competition) or the vertical externality (due to double markup), which benefits the merging firms.

R2: A merger always hurts other firms and consequently a breakup always benefits other firms. By eliminating double markup, a vertical merger makes the merged entity more aggressive in the downstream competition, which hurts the remaining firms. A horizontal merger between duopolists will hurt the other industry by reducing quantities supplied or demanded.

R3: $S_{1}$ Pareto dominates $S_{3}$, which in turn dominates $S_{2}$. Firms face horizontal externality in $S_{3}$ and therefore tend to produce too much from the viewpoint of their joint profits. They face vertical externality in $S_{2}$ and tend to produce too little. Both externalities are present in $S_{1}$, but their opposite effects mitigate each other, so $S_{1}$ dominates both $S_{2}$ and $S_{3}$. The horizontal externality in $S_{3}$ is moderate because the downstream competition (Cournot rather than Bertrand) is mild, while the vertical externality in $S_{2}$ is severe because it leads to successive monopoly, so $S_{3}$ dominates $S_{2}$.

These three profit ranks help us understand the intuition for stable structures. First, it cannot be stable to have only one merger because the remaining two independent firms will be better off merging. They gain if the originally merged firm remains merged (R1) and will gain even more if the merged firm breaks up (R2). Second, having two horizontal mergers is unstable, as an upstream firm and a downstream firm would rather merge vertically. Such a 
deviation is profitable if the other two firms also merge vertically $(R 3)$ and is even more profitable if the other two firms do not merge ( $R 2)$.

That leaves two configurations: all firms remain independent $\left(S_{1}\right)$ or carry out two vertical mergers $\left(S_{3}\right)$. Both are stable. Consider first the no-merger case. An exogenous merger would have been profitable (R1). However, if the other two firms also merge, the participants in the first merger would be worse off $(R 3)$. Therefore, no deviation (in the form of a merger) will be carried out in $S_{1}$. Now consider two vertical mergers. It is unprofitable to either break up (if the other merged firm remains merged $-R 1$ ) or switch to a horizontal merger (if the other two firms also merge horizontally $-R 3$ ).

The stable market structures depicted in Proposition 1 display some interesting features. We would like to highlight four of them. First, mergers occur in waves. Proposition 1 reveals that it is stable to have two vertical merged firms $\left(S_{3}\right)$ and unstable to have a single merger $\left(S_{4}, S_{5}\right.$, and $\left.S_{6}\right)$. Therefore, whenever a merger occurs, it must be accompanied by another. A single merger hurts the other two firms, which will then find it profitable to merge regardless of what the first pair does (dissolves or remains merged). So the driving force for mergers to cluster is the negative impact of a merger on other firms.

Second, it is also stable for all four firms to remain independent $\left(S_{1}\right)$ even though any individual merger would have been profitable. When a given merger is said to be profitable, the configuration among the remaining two firms is implicitly assumed to be fixed, i.e. they remain independent. If those two firms also merge, however, the first pair will be hurt. Concerns about a second merger's negative impact therefore prevent the first merger from taking place.

Third, a merger wave may take place without any fundamental change in the underlying conditions. Proposition 1 predicts two stable configurations: The firms may remain in $S_{1}$ (or 4I, meaning four independent firms, for a more informative notation) or they may carry out two vertical mergers, ending up with $S_{3}$ (or $2 \mathrm{~V}$ ). A change of the market structure from $4 \mathrm{I}$ to $2 \mathrm{~V}$ duly endogenizes the vertical merger wave. Because the two structures are stable under the same conditions, shifting from $4 \mathrm{I}$ to $2 \mathrm{~V}$ does not require any change in the economic fundamentals such as demand or technology. The trigger may be something trivial or totally unrelated: mood, expectation, rumor, etc. ${ }^{11}$

11 Although $4 \mathrm{I}$ and $2 \mathrm{~V}$ are both stable, they are not on an equal footing. Switching from $4 \mathrm{I}$ to $2 \mathrm{~V}$ is possible or even likely because if, for whatever reason, a pair of firms expect the other pair to merge, they will prepare to follow suit. The reverse process of jumping from $2 \mathrm{~V}$ to $4 \mathrm{I}$, a divestiture wave, is more difficult. If for some reason a pair breaks up, it is in the best interest of the second pair not to follow. This asymmetry between the two stable configurations may explain why in real life merger waves are much more common than divestiture waves. 
Fourth, a merger wave could be vertical or horizontal depending on the tradeoff between the vertical and horizontal externalities. In a $2 \times 2$ setting a merger wave may consist of two vertical mergers $(2 \mathrm{~V})$ or two horizontal mergers $\left(S_{2}\right.$ or $\left.2 \mathrm{H}\right)$, referred to, respectively, as vertical and horizontal merger waves. A firm chooses a vertical or horizontal merger taking into account possible reactions by the remaining firms, so ultimately it is a choice between $2 \mathrm{~V}$ and $2 \mathrm{H}$. As mentioned earlier, $2 \mathrm{~V}$ eliminates double markup but intensifies horizontal competition; $2 \mathrm{H}$ does the opposite. In this example's particular setting, the damage of double markup is greater than that of horizontal competition, so the firms end up making two vertical mergers. In more general settings, however, the comparison may be reversed and horizontal mergers may emerge in equilibrium. If, for example, the competition is à la Bertrand rather than Cournot, a merger wave could be horizontal.

\section{Analysis}

The example in the previous section analyzes merger waves in a specific setting. To better understand why and how merger waves take place, it is necessary to change the demand and cost conditions and the nature of competition in a systematic way. In what follows, we will allow product differentiation, nonlinear cost or demand, and price/quantity competition. As will be clear shortly, these settings directly affect the competition intensity along upstream, downstream and vertical dimensions, which turns out to be crucial for merger waves.

\subsection{Product Differentiation}

Suppose that the final products are differentiated (though the inputs are still homogeneous) with linear demand. Let the demand for firm $i$ 's product be $p_{i}=\alpha-q_{i}-\beta q_{j}$, where $i, j \in\{1,2\}$ with. $i \neq j$, and $\left.\beta \in 0,1\right]$ represents the degree of product differentiation. Further, assume that each industry may compete on either quantity or price. This gives rise to the following three combinations: Cournot competition in both industries (Cournot-Cournot); upstream Cournot competition and downstream Bertrand competition (Cournot-Bertrand); and Bertrand competition in both industries (Bertrand-Bertrand). For each of the three cases, a payoff table similar to Table 1 can be constructed (an example is shown in the Appendix), where each payoff is a function of $\beta$ only. ${ }^{12}$

12 Again, $\alpha-c$ can be normalized without losing any generality. 


\section{Proposition 2.}

(1) In the Cournot-Cournot case, $S_{1}$ is stable for $\beta>0.29$ and $S_{3}$ is stable for any $\beta$.

(2) In the Cournot-Bertrand case, $S_{1}$ is stable for $0.22<\beta<0.8, S_{2}$ is stable for $\beta>0.66$, and $S_{3}$ is stable for $\beta<0.66$.

(3) In the Bertrand-Bertrand case, $S_{3}$ is stable for.. and $S_{2}$ is stable for any $\beta$.

Proof: See the Appendix.

As Proposition 2 suggests, a single merger $\left(S_{4}, S_{5}\right.$, and $\left.S_{6}\right)$ can never be stable. The reason has been discussed in the example and will be further elaborated later. The remaining three configurations, no-merger $\left(S_{1}\right)$ and horizontal and vertical merger waves $\left(S_{2}\right.$ and $\left.S_{3}\right)$, can all be stable under certain conditions. A general pattern is that as competition intensifies (moving from Cournot to Bertrand), horizontal mergers become more likely, while vertical mergers and no-merger become less likely.

The equilibrium results shown in Table 2 exemplify the implications of Proposition 2. The parameter range indicates the condition for a particular configuration to be stable, and the parenthesis below indicates the profitable deviation that makes the configuration unstable when the condition is violated. For example, in the Cournot-Cournot case, $S_{1}$ is stable for $\beta>0.29$. If $\beta<0.29$, $S_{1}$ becomes unstable because $A+B$ is a profitable deviation.

Table 2: Results of Propositions 2 and 3.

\begin{tabular}{llll}
\hline Cases & $\boldsymbol{S}_{\mathbf{1}}(\mathbf{4})$ & $\boldsymbol{S}_{\mathbf{2}}(\mathbf{2 H})$ & $\boldsymbol{S}_{\mathbf{3}}(\mathbf{2 V})$ \\
\hline Cournot-Cournot & $\beta>0.29$ & Never & Always \\
& $(A+B)$ & $(A+1)$ & \\
Cournot-Bertrand & $0.22<\beta<0.80$ & $\beta>0.66$ & $\beta<0.66$ \\
& $(A+B)(1+2)$ & $(A+1)$ & $(A+B)$ \\
Bertrand-Bertrand & Never & Always & $\beta<0.66$ \\
& $(A+B)$ & & $(A+B)$ \\
Increasing mc & $\gamma<2$ & $\gamma>2$ & $\gamma<2$ \\
General demand & $(1+2)$ & $(A+1)$ & $(1+2)$ \\
& Always & $\sigma>1$ & $\sigma \leq 1$ \\
& & $(A+1)$ & $(A+B)$ \\
\hline
\end{tabular}

\subsubsection{Cournot-Cournot}

The setting is the same as in the example except that the final products are differentiated, so the example is a special case with $\beta=1$. Greater differentiation 
between the final products weakens the downstream competition. If products are sufficiently differentiated ( $\beta$ is small), the downstream horizontal externality is greatly weakened. 4I is no longer stable because there is no need to use vertical externality to mitigate the horizontal externality. In the example, $2 \mathrm{~V}$ dominates $2 \mathrm{H}$ because downstream horizontal competition is less damaging than double markup. Product differentiation further reduces the damage of horizontal competition, so $2 \mathrm{~V}$ is always stable for any $\beta$ while $2 \mathrm{H}$ is never stable.

\subsubsection{Cournot-Bertrand}

When downstream firms compete on price rather than quantity, downstream competition is intensified. $4 \mathrm{I}$ is stable only if the products are modestly differentiated (intermediate $\beta$ ). When products are highly differentiated the downstream competition is too weak; when products are close substitutes the downstream competition is too strong. $4 \mathrm{I}$ is unstable in either case. As explained earlier, product differentiation favors $2 \mathrm{~V}$ over $2 \mathrm{H}$, so $2 \mathrm{~V}$ continues to be stable when products are sufficiently differentiated (small $\beta$ ). Conversely, when products are close substitutes (large $\beta$ ), fierce competition in the downstream industry raises both the benefits of horizontal mergers and the drawbacks of vertical mergers, so $2 \mathrm{H}$ becomes stable.

\subsubsection{Bertrand-Bertrand}

The upstream firms also compete on price now, so upstream competition is intensified. In fact it is intensified to the greatest extent as inputs are homogeneous. 4I is never stable because upstream firms earn zero profits in the 4I situation and they will always attempt to merge. As in the previous case, $2 \mathrm{~V}$ is stable when the products are sufficiently differentiated. $2 \mathrm{H}$ is stable for any $\beta$ because the upstream horizontal competition is too strong. ${ }^{13}$

\subsection{Cost and Demand}

We now move back to the setting with a homogeneous final product and Cournot competition in both industries, and change the cost or demand, one

13 Starting from $2 \mathrm{H}$, if an upstream and a downstream firm deviate to form a vertical merger, one scenario they may face is that the other two firms do not merge. The upstream firm's profit share in the merger will then be very low because it is calculated based on the situation where the merger does not take place, in which case its profit will be zero due to upstream price competition. 
at a time. There are two cases. In the increasing marginal cost case, the cost of input production is $C(q)=\gamma q^{2}$ with $\gamma \geq 0$, while the demand for the final product continues to be linear $(p=\alpha-Q)$. Note that the example in Section 3 is a special case of increasing $m c$ with $\gamma=0 .{ }^{14}$ If $\gamma>0$, marginal cost $(m c)$ increases with production quantity. In the general demand case, the demand for the final product is $p=\alpha-Q^{\sigma}$ with $\alpha>0$ and $\sigma>0$, while the input cost is linear $(C(q)=c q)$. Again the example is a special case with $\sigma=1$. Note a peculiar property of this general demand function: Its concavity, defined as $\frac{p^{\prime \prime}(Q) Q}{p^{\prime}(Q)}$, is constant. ${ }^{15}$

\section{Proposition 3.}

(1) In the increasing marginal cost case with $C(q)=\gamma q^{2}, S_{1}$ and $S_{3}$ are stable for $\gamma<2$, and $S_{2}$ is stable for $\gamma>2$.

(2) In the general demand case with $p=\alpha-Q^{\sigma}, S_{1}$ is stable for any $\sigma, S_{2}$ is stable for $\sigma>1$, and $S_{3}$ is stable when $\sigma \leq 1$.

Proof: See the Appendix.

The results of Proposition 3 have already been summarized in Table 2. Again, a single merger $\left(S_{4}, S_{5}\right.$, and $\left.S_{6}\right)$ is never stable.

\subsubsection{Increasing Marginal Cost}

Producing the inputs at increasing marginal cost will reduce the upstream competition. ${ }^{16}$ When the $m c$ curve is steep ( $\gamma$ is large), $4 \mathrm{I}$ is unstable because an upstream merger will not raise the input price by much and therefore will do little damage to the downstream firms. As a result, the downstream firms will find it profitable to merge. An increasing marginal cost favors $2 \mathrm{H}$ over $2 \mathrm{~V}$. The benefit of a vertical merger comes from output expansion due to the elimination of double markup. When the marginal cost of the input increases with quantity, expansion is increasingly costly, so the benefits of vertical mergers decrease.

14 In the example the exact value of $c$ is inconsequential, as all profits are proportional to $(\alpha-c)^{2}$ and consequently $\alpha-c$ has been normalized without any loss of generality. We may as well think that $c=0$.

15 In fact, $\frac{p^{\prime \prime}(Q) Q}{p^{\prime}(Q)}=\sigma-1$. This function has been used by Greenhut and Ohta (1976) and other scholars of merger incentives and/or vertically related industries.

16 In terms of oligopoly behavior, product homogeneity with increasing marginal costs is mathematically equivalent to product differentiation with constant marginal cost (Vives 1999). In a sense, the increasing marginal cost considered here introduces differentiation to the inputs. 
When the $m c$ curve is flat ( $\gamma$ is small), such a decrease is small, so $2 \mathrm{~V}$ continues to dominate $2 \mathrm{H}$, meaning that $2 \mathrm{~V}$ is stable while $2 \mathrm{H}$ is not.

\subsubsection{General Demand}

An increase in the concavity of demand lessens the severity of the double markup problem. ${ }^{17}$ As will be argued below, 4I is always threatened by horizontal mergers rather than vertical ones. But demand concavity affects mainly double markup, which is present in both the $4 \mathrm{I}$ and $2 \mathrm{H}$ configurations, so $2 \mathrm{H}$ is never a real threat and consequently $4 \mathrm{I}$ is stable for any value of the demand's concavity. When the demand is convex $(\sigma<1)$ the double markup problem is very severe, so firms merge vertically to avoid the damage, leading to $2 \mathrm{~V}$. Conversely, when the demand is concave $(\sigma>1)$ double markup is less of a problem. Avoiding horizontal competition becomes the major concern, so $2 \mathrm{H}$ is stable.

\subsection{Discussion}

As was seen with the example, the stability of a configuration depends crucially on the relative intensity of double markup and horizontal competition in the two industries. Each of the five variation settings introduces a parameter that affects one of the three intensities. Compared to the example, differentiation of the final products (Cournot-Cournot) weakens the downstream competition; Bertrand competition downstream (Cournot-Bertrand) intensifies the downstream competition; Bertrand competition upstream (Bertrand-Bertrand) intensifies the upstream competition. Increasing marginal cost for input production weakens the upstream competition, whereas greater demand concavity lessens the severity of double markup. The stable structures of the five variation settings are presented graphically in Figure 1, where the bullet point represents the example's result as a special case.

17 A single-level monopolist facing constant marginal cost $c$ and demand $p=\alpha-Q^{\sigma}$ will choose quantity... In successive monopoly with the same cost and demand, the quantity chosen will be $Q_{2}=\left[\frac{\alpha-c}{(1+\sigma)^{2}}\right]^{\frac{1}{\sigma}}<Q_{1}$. As a measure of the severity of double markup, $\frac{Q_{1}}{Q_{2}} \equiv(1+\sigma)^{\frac{1}{\sigma}}$ declines with $\sigma$, indicating that double markup is less of a problem when $\sigma$ increases. Basically, when $\sigma$ is larger, the demand for input is closer to the demand for the final product. 
Cournot-Cournot

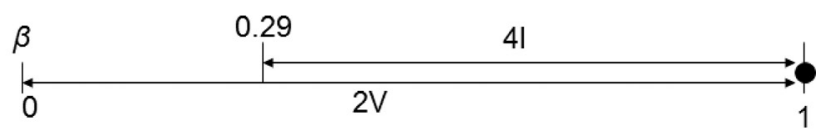

Cournot-Bertrand

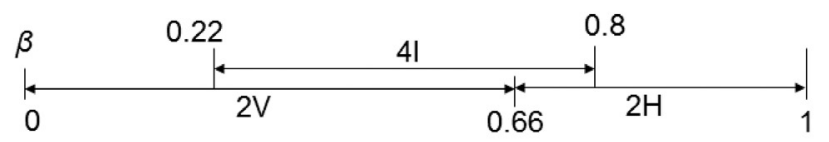

Bertrand-Bertrand

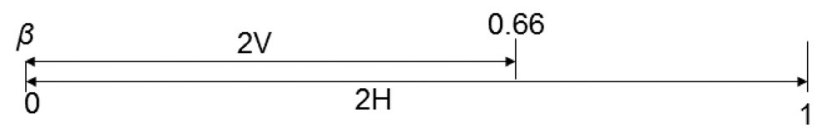

Increasing mc

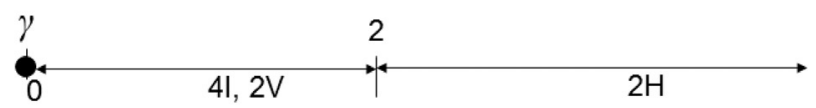

General demand

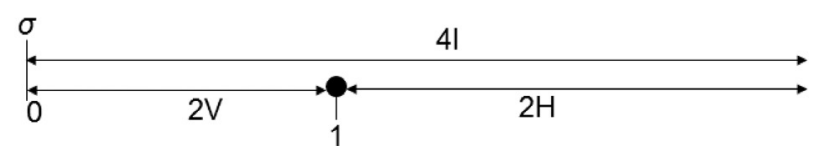

Figure 1: Stable configurations in the five variation settings.

\subsubsection{Merging in Waves}

In all cases with any parameter values, there is always a stable configuration involving two mergers, either horizontal or vertical, while a single merger $\left(S_{4}, S_{5}\right.$, and $\left.S_{6}\right)$ is never stable. So mergers always come in waves. The driving force is still the two profitability rankings seen in the example. An exogenous merger between any two firms is always profitable $(R 1)$, and a merger always hurts other firms $(R 2)$. Below we explain why they still hold in general. Once they are established, our game rule immediately implies that configurations with only single merger can never be stable.

Consider first the configuration with only a vertical merger $\left(S_{4}\right)$. The merged firm becomes more competitive in the downstream competition, so the merger hurts the other two firms. Fixing the first merger, a merger between the remaining two firms is profitable because it internalizes the vertical externality generated by double markup.

Next consider the configuration with only an upstream horizontal merger $\left(S_{5}\right)$. This merger raises the input price and thereby hurts downstream firms. Fixing the upstream merger, the downstream firms can merge from duopoly to monopoly, which should always be profitable. But the complication is the 
presence of the upstream industry. In particular, upstream firms may try to share the benefit of the downstream merger by raising the input price, which will reduce the profitability of the downstream merger. However, it can be verified that in all the settings we have considered so far, a downstream merger never changes the equilibrium input price. ${ }^{18}$ As a result, a downstream merger continues to be profitable despite the upstream industry's response.

Finally consider the configuration with only a downstream horizontal merger $\left(S_{6}\right)$. This merger reduces the quantity of inputs demanded without changing the input price, so it hurts upstream firms. Fixing the downstream merger, the upstream firms may merge from duopoly into a monopoly, which again should always be profitable. And again the complication is the presence of a vertically related industry downstream. However, the demand that upstream firms face is derived from the downstream competition. As long as the downstream configuration is fixed, that demand does not change. An upstream merger continues then to be profitable despite the downstream industry's response.

\subsubsection{The Stability of Not Merging}

In all cases except Bertrand-Bertrand competition, it is stable under certain conditions for all firms to remain independent (4I). Firms in 4I may deviate into either a horizontal or a vertical merger, but what really matters is how the deviators expect to do in a situation where the other two firms also merge. That is, the alternative to $4 \mathrm{I}$ is essentially a merger wave resulting in either $2 \mathrm{H}$ or $2 \mathrm{~V}$.

The stability of 4I depends on the four firms' total profits and their distribution among them. In terms of total profits, $4 \mathrm{I}$ tends to outperform both $2 \mathrm{H}$ and 2V. In all cases except Bertrand-Bertrand competition, 2V eliminates double markup but retains horizontal competition, so the firms over-produce from the viewpoint of their joint profits, a horizontal externality. By contrast, $2 \mathrm{H}$ removes horizontal competition but retains double markups, so the firms under-produce, which can be viewed as a vertical externality. 4I has both externalities, but since

18 In the example, the equilibrium input price is $t=c+\frac{\alpha-c}{(u+1)(v+1)}$, which does not depend on $d$. So if there is a downstream merger (i.e. $d$ decreases by 1 ), the equilibrium input price will not change. A downstream merger rotates the demand for inputs clockwise around the intercept. This rotation has two opposite effects on $t$ : For any given $t$, the quantity demanded is smaller, so $t$ tends to drop. At the same time, the demand becomes less elastic, so $t$ tends to rise. In the case of linear demand for the final product, the two forces exactly cancel each other so the equilibrium input price will be independent of the number of downstream firms. For non-linear demand, Greenhut and Ohta (1976) and Ziss (2005) have shown the same invariance as long as the demand has constant concavity, which is satisfied by the general demand adopted here. 
the two externalities move in opposite directions, one mitigates the other and the firms' total profits tend to increase.

The distribution of the total profit also matters for the stability of 4I. For a deviating vertical merger in $4 \mathrm{I}$ to be profitable, the merging pair will have to earn more. Because the two vertical pairs are symmetrical, the four firms' total profits must therefore be higher in $2 \mathrm{~V}$ than in 4I, which is unlikely. By contrast, 4I can easily be disrupted by a horizontal merger; such a deviation need only benefit one horizontal pair, not both. So the stability of $4 \mathrm{I}$ is always threatened by a horizontal merger, not a vertical one.

Whether or not the threat will materialize depends on the relative intensity of horizontal competition in the upstream and downstream industries. If the two competitions are more or less balanced, 4I can be stable. For example, in the Bertrand-Bertrand situation, the upstream competition is very strong, so $4 \mathrm{I}$ is never stable at any $\beta$. In the Cournot-Bertrand situation, the competition is balanced only for moderate differentiation in the final products.

\subsubsection{Vertical and Horizontal Merger Waves}

In all cases and with any parameter values there is always a stable configuration involving two mergers, either horizontal $(2 \mathrm{H})$ or vertical (2V). Furthermore, except with Bertrand-Bertrand competition, the two structures are mutually exclusive: When $2 \mathrm{H}$ is stable, $2 \mathrm{~V}$ is unstable, and vice versa. For $2 \mathrm{H}$, the threat to stability comes mainly from a vertical merger. Given the assumptions, the deviating firms are mainly concerned about the situation in which the other two firms also merge vertically, so the alternative market structure to $2 \mathrm{H}$ is basically $2 \mathrm{~V}$. Similarly, the alternative to $2 \mathrm{~V}$ is $2 \mathrm{H}$. Therefore, $2 \mathrm{H}$ and $2 \mathrm{~V}$ will be essentially the only market structures that the firms consider when they ponder a merger or deviation. At any given set of parameter values, either $2 \mathrm{H}$ dominates $2 \mathrm{~V}$ (for a horizontal pair) or $2 \mathrm{~V}$ dominates $2 \mathrm{H}$ (for both vertical pairs), so one and only one of the two configurations is stable.

Which is stable depends crucially on how the total profits distribute among the four firms, which in turn depends on the relative intensity of upstream and downstream competition. Because firms within an industry are assumed symmetric, the two vertical pairs are symmetric while the two horizontal pairs are not. For $2 \mathrm{H}$ to be stable, $2 \mathrm{H}$ needs to dominate $2 \mathrm{~V}$ for only one horizontal pair, either upstream or downstream. By contrast, for $2 \mathrm{~V}$ to be stable, $2 \mathrm{~V}$ has to dominate $2 \mathrm{H}$ for all four firms. When competition in both industries is balanced, $2 \mathrm{~V}$ tends to be stable. When an industry's competition is greatly intensified or weakened, $2 \mathrm{H}$ tends to be stable. For example, price (rather than quantity) 
competition or closer substitutability between final products will lead to a horizontal merger wave. Greatly weakened competition in the upstream industry, due to increasing marginal costs of input production, will have a similar effect, because downstream competition is now relatively intensified and firms there would like to merge horizontally. These results demonstrate that changes of competition in one industry may induce mergers in a vertically related industry.

To summarize, both $4 \mathrm{I}$ and $2 \mathrm{~V}$ are disrupted by $2 \mathrm{H}$, while $2 \mathrm{H}$ is disrupted by $2 \mathrm{~V}$. $4 \mathrm{I}$ tends to outperform both $2 \mathrm{H}$ and $2 \mathrm{~V}$ in terms of the four firms' total profits. Between $2 \mathrm{H}$ and $2 \mathrm{~V}$, the comparison of total profits depends on the tradeoff between double markup and downstream horizontal competition. For example, when the demand for the final products is convex, double markup is a severe problem, so $2 \mathrm{~V}$ prevails. When the downstream competition is Bertrand and the final products are close substitutes, the downstream competition is intense, so firms merge horizontally. These predictions are straightforward. More interesting and somewhat surprising is the role of the relative intensity of competition in the two industries. When the intensities are balanced, both $4 \mathrm{I}$ and $2 \mathrm{~V}$ tend to be stable. When the competition in one industry is greatly intensified or weakened, $2 \mathrm{H}$ tends to be stable.

\subsubsection{Two triggers of Merger Waves}

A model of endogenous merger waves must explain not only why a merger wave takes place, but also why it did not take place earlier. In other words, the structure before and after the wave must both be stable. As Figure 1 indicates, in all five cases at any parameter value, there are at most two stable configurations and at least one. For some ranges of the parameters there is a unique stable configuration, which invariably contains two mergers, either $2 \mathrm{~V}$ or $2 \mathrm{H}$. If the parameter falls into that range, the mergers should take place immediately, so the only explanation for why they did not take place earlier is that the parameter was outside the range, where it was stable for all firms to remain independent. Such a change of parameter value can be interpreted as an economic shock. For example, in the Cournot-Cournot situation, $2 \mathrm{~V}$ is the unique equilibrium for $\beta<0.29$, and $4 \mathrm{I}$ is an equilibrium (though not unique) for $\beta>0.29$. If $\beta$ drops from a value greater than 0.29 to a value below it, the industry will undergo a wave of vertical mergers. So an increase in the differentiation of the final products (due to, say, more investment in R\&D or advertising) may trigger a vertical merger wave. Likewise, a more convex demand curve may also trigger a vertical merger wave. Similarly, a horizontal merger wave may 
be triggered by greater substitutability between the final products (CournotBertrand), steeper marginal cost in input production, or greater concavity of demand.

For some other ranges of the parameters there are exactly two stable structures, and in most cases one is $4 \mathrm{I}$ and the other is either $2 \mathrm{~V}$ or $2 \mathrm{H}$. When that is the case, it is possible for a merger wave to take place without any change in the underlying economic conditions, as the example shows. For example, a vertical merger wave is possible when the products are close substitutes (Cournot-Cournot), when marginal cost rises slowly, or when the demand is convex. A horizontal merger wave can occur when product differentiation is moderate (Cournot-Bertrand) or the demand is concave.

So both tangible and intangible causes may trigger a merger wave. ${ }^{19} \mathrm{~A}$ tangible trigger is an economic shock that changes business conditions. An intangible trigger might be a rumor or a sudden change in expectations or mood that shifts the market structure between two stable configurations without any change in the underlying economic conditions.

The equilibrium may also switch between $2 \mathrm{H}$ and $2 \mathrm{~V}$. In a sense this is also a merger wave, although it involves more restructuring because firms have to disintegrate and then re-integrate. Both tangible and intangible triggers also can be found for such merger waves. For example, with Bertrand-Bertrand competition the economy may switch from $2 \mathrm{~V}$ to $2 \mathrm{H}$, the pattern of structural changes observed in the semiconductor industry. Such a wave of vertical disintegration followed by horizontal integration can have an intangible trigger when the products are poor substitutes, or a tangible trigger when the final products become closer substitutes.

\section{Conclusions}

We have studied merger waves in vertically related industries where firms can engage in both vertical and horizontal mergers. Whether, why and how a merger wave takes place has been shown to depend on the balance between vertical and horizontal externalities and the balance between upstream and downstream competition. A merger wave may happen with or without any fundamental change in the underlying economic conditions. The research has generated

19 In a study of horizontal mergers, Toxvaerd (2008) found no-merger and multiple mergers to be equilibrium under identical or different conditions, which could imply the two types of triggers. 
many empirically testable predictions relating merger waves to conditions such as product differentiation, cost structure, and demand concavity.

Although the particular equilibria are derived based on the specific equilibrium concept and number of firms, the general conclusions seem robust because the driving force is the total profits and their distribution among the firms, which are model-independent, relating only to the relative strength between double markup and upstream and downstream competition. The equilibrium concept was adopted from the matching literature, and it served our purpose well, as other equilibrium concepts from the coalition-formation literature are either too strong so that the equilibrium set is empty, or too weak so that the set is too large.

The simplest possible setting with two upstream and two downstream firms has been used. In this setting an exogenous merger always benefits the merging firms and hurts non-merging firms. These effects conform to common understanding of what a merger means, particularly for vertically related industries, and they hold regardless of whether firms compete on price or quantity. The drawback is that horizontal and vertical merger waves cannot coexist. Merging from duopoly into a monopoly is also special. If each industry has more than two firms, one concern is that a two-firm merger may not be profitable (Salant, Switzer, and Reynolds 1983). This can be dealt with by allowing mergers to generate synergies. ${ }^{20}$ Our purpose is not to explain the profitability of any single merger. Rather, we treat the profitability as given and focus on the interaction between mergers.

Merger decisions in this model are made simultaneously. A sequential game would have the advantage of generating strategic incentives for mergers and may therefore yield other explanations for merger waves (Qiu and Zhou 2007). But the disadvantage is that the equilibrium will be sensitive to the order of moves and other details of the game, ${ }^{21}$ which a researcher has no compelling reason or sufficient information to specify exogenously. So this study has adopted a simultaneous game and an equilibrium concept borrowed from one-to-one matching games with externalities. This has enabled

20 This can be easily done with product differentiation, increasing marginal costs, or constant but differential marginal costs. In a $3 \times 3$ setting without synergies, the Appendix shows that there are two equilibria, one in which all firms remain independent and the other in which three vertical mergers take place. Similar patterns have been found in the $3 \times 4,4 \times 3,4 \times 4$, and more general $n \times m$ settings (Yao and Zhou 2011).

21 For example, Colangelo's (1995) sequential game leads to very different predictions about the equilibrium market structure depending on the identity of the first acquisition target, which is exogenously given. 
us to capture the essential interdependence of merger incentives without having to specify the details. It may therefore prove useful in studying other merger-related issues.

The merger surplus was calculated assuming a fixed configuration among remaining firms, which seems to contradict the idea that firms consider all possible configurations when contemplating a merger. However, if configurations are allowed to vary in calculating profit sharing, the profits will be illdefined because there are multiple configurations. The assumption of fixed and equal sharing rule between merger partners is not as strong as it seems, because the major conclusion is driven by the relative intensity of vertical and horizontal externalities/competition, which is independent of the concrete sharing rule. The assumption of arm's length transaction may seem problematic when an industry has only one firm, but what is really needed is double markup and the property that vertical transactions depend on the market structure in both industries. Such assumptions are relevant in many situations. An alternative to arm's length transactions may be two-part tariff. The Bertrand-Bertrand assumption removes double markup and may therefore have already captured what will happen when a two-part tariff is used between upstream and downstream firms.

This has been a first step in studying endogenous merger waves in vertically related industries. Many interesting extensions remain to be explored, such as asymmetric firms, dynamic game rules, and more sophisticated settings and sharing rules.

\section{Appendix}

\section{Procedures for Proving Propositions 2 and 3}

The calculation and proofs are tedious. Here we provide only the procedures. In each case, we construct a payoff table similar to Table 1. Each payoff will be a function containing a single parameter (it turns out that $\alpha-c$ can be normalized to 1 without any loss of generality). For example, in the Cournot-Cournot case the following payoff table results. Other tables are available from the corresponding author on request.

Given the payoffs, the stability of each configuration is easily examined. For a configuration to be stable, every possible deviation must be checked to show that it is unprofitable for at least one firm. For a configuration to be unstable, we 
Table 3: Payoffs in the Cournot-Cournot case.

\begin{tabular}{llllll}
\hline Configuration & $\pi_{\boldsymbol{A}}$ & $\boldsymbol{\pi}_{\boldsymbol{B}}$ & $\boldsymbol{\pi}_{\mathbf{1}}$ & $\boldsymbol{\pi}_{\mathbf{2}}$ & Total profits \\
\hline$S_{1}=\{A, B ; 1,2\}$ & $\frac{2}{9(2+\beta)}$ & $\frac{2}{9(2+\beta)}$ & $\frac{4}{9(2+\beta)^{2}}$ & $\frac{4}{9(2+\beta)^{2}}$ & $\frac{4(4+\beta)}{9(2+\beta)^{2}}$ \\
$S_{2}=\{A B ; 12\}$ & $\frac{1}{8(1+\beta)}$ & $\frac{1}{8(1+\beta)}$ & $\frac{1}{16(1+\beta)}$ & $\frac{1}{16(1+\beta)}$ & $\frac{3}{8(1+\beta)}$ \\
$S_{3}=\{A 1, B 2\}$ & $\frac{10-\beta^{2}}{16(2+\beta)^{2}}$ & $\frac{10-\beta}{16(2+\beta)^{2}}$ & $\frac{6+\beta^{2}}{16(2+\beta)^{2}}$ & $\frac{6+\beta^{2}}{16(2+\beta)^{2}}$ & $\frac{2}{(2+\beta)^{2}}$ \\
$S_{4}=\{A 1, B, 2\}$ & $\frac{144+104 \beta+9 \beta^{2}}{288(2+\beta)^{2}}$ & $\frac{2-\beta}{8(2+\beta)}$ & $\frac{144+40 \beta+9 \beta^{2}}{288(2+\beta)^{2}}$ & $\frac{1}{4(2+\beta)^{2}}$ & $\frac{28+8 \beta-\beta^{2}}{16(2+\beta)^{2}}$ \\
$S_{5}=\{A B ; 1,2\}$ & $\frac{1}{4(2+\beta)}$ & $\frac{1}{4(2+\beta)}$ & $\frac{1}{4(2+\beta)^{2}}$ & $\frac{1}{4(2+\beta)^{2}}$ & $\frac{3+\beta}{2(2+\beta)^{2}}$ \\
$S_{6}=\{A, B ; 12\}$ & $\frac{1}{9(1+\beta)}$ & $\frac{1}{9(1+\beta)}$ & $\frac{1}{9(1+\beta)}$ & $\frac{1}{9(1+\beta)}$ & $\frac{4}{9(1+\beta)}$ \\
\hline
\end{tabular}

need to only find one deviation that is profitable for both deviators (when it is a joint deviation).

For $S_{1}=\{A, B ; 1,2\}$ to be stable: (i) $A+B$ is unprofitable: $\pi_{A}^{S_{1}}>\min \left\{\pi_{A}^{S_{2}}, \pi_{A}^{S_{5}}\right\}$; (ii) $1+2$ is unprofitable: $\pi_{1}^{S_{1}}>\min \left\{\pi_{1}^{S_{2}}, \pi_{1}^{S_{6}}\right\}$; and (iii) $A+1$ is unprofitable: $\pi_{i}^{S_{1}}>\min \left\{\pi_{i}^{S_{3}}, \pi_{i}^{S_{4}}\right\}$ for $i=A$ or 1 .

For $S_{2}=\{A B ; 12\}$ to be stable: (i) Breaking $A B$ is unprofitable: $\pi_{A}^{S_{2}}>\min \left\{\pi_{A}^{S_{1}}, \pi_{A}^{S_{6}}\right\}$; (ii) breaking 12 is unprofitable: $\pi_{1}^{S_{2}}>\min \left\{\pi_{1}^{S_{1}}, \pi_{1}^{S_{5}}\right\}$; and (iii) $A+1$ is unprofitable: $\pi_{i}^{S_{2}}>\min \left\{\pi_{i}^{S_{3}}, \pi_{i}^{S_{4}}\right\}$ for $i=A$ or 1 .

For $S_{3}=\{A 1, B 2\}$ to be stable: (i) Breaking $B 2$ is unprofitable: $\pi_{i}^{S_{3}}>\min \left\{\pi_{i}^{S_{1}}, \pi_{i}^{S_{4}}\right\} \quad$ for $\quad i=B$ and 2 ; $\quad$ (ii) $A+B$ is unprofitable: $\pi_{A}^{S_{3}}>\min \left\{\pi_{A}^{S_{2}}, \pi_{A}^{S_{5}}\right\}$; and (iii) $1+2$ is unprofitable: $\pi_{1}^{S_{3}}>\min \left\{\pi_{1}^{S_{2}}, \pi_{1}^{S_{6}}\right\}$.

For $S_{4}=\{B ; A 1,2\}$ to be unstable, we only need one of following cases to hold: (i) $B+2$ is profitable: $\pi_{i}^{S_{4}}<\min \left\{\pi_{i}^{S_{3}}, \pi_{j}^{S_{4}}\right\}$ for both $\{i=B, j=A\}$ and $\{i=2, j=1\}$; (ii) $A+B$ is profitable: $\pi_{A}^{S_{4}}<\min \left\{\pi_{A}^{S_{2}}, \pi_{A}^{S_{5}}\right\}$; (iii) $1+2$ is profitable: $\pi_{1}^{S_{4}}<\min \left\{\pi_{1}^{S_{2}}, \pi_{1}^{S_{6}}\right\}$; (iv) Breaking A1 is profitable: $\pi_{i}^{S_{4}}<\min \left\{\pi_{i}^{S_{1}}, \pi_{j}^{S_{4}}\right\}$ for either $\{i=A, j=B\}$ or $\{i=1, j=2\}$; (v) $A+2$ is profitable: $\pi_{i}^{S_{4}}<\min \left\{\pi_{i}^{S_{3}}, \pi_{j}^{S_{4}}\right\}$ for both $i=j=A$ and $\{i=2, j=1\}$; and (vi) $B+1$ is profitable: $\pi_{i}^{S_{4}}<\min \left\{\pi_{i}^{S_{3}}, \pi_{j}^{S_{4}}\right\}$ for both $\{i=B, j=A\}$ and $i=j=1$.

For $S_{5}=\{A B ; 1,2\}$ to be unstable: $1+2$ is profitable since $\pi_{1}^{S_{5}}<\min \left\{\pi_{1}^{S_{2}}, \pi_{1}^{S_{6}}\right\}$.

For $S_{6}=\{A, B ; 12\}$ to be unstable: $A+B$ is profitable since $\pi_{A}^{S_{6}}<\min \left\{\pi_{A}^{S_{2}}, \pi_{A}^{S_{5}}\right\}$. 


\section{The $3 \times 3$ Case}

Suppose there are three identical upstream firms $(A, B, C)$ and three identical downstream firms $(1,2,3)$. The other assumptions remain the same as in the example. There are then 10 possible market configurations as shown in the following payoff table. As the next proposition reveals, the firms will either all remain independent or carry out three vertical mergers, which is consistent with the result of the example.

Table 4: Payoffs in the $3 \times 3$ case.

\begin{tabular}{llllllll}
\hline Configurations & \multicolumn{1}{c}{$\boldsymbol{\pi}_{\boldsymbol{A}}$} & \multicolumn{1}{c}{$\boldsymbol{\pi}_{\boldsymbol{B}}$} & \multicolumn{1}{c}{$\boldsymbol{\pi}_{\boldsymbol{C}}$} & \multicolumn{1}{c}{$\boldsymbol{\pi}_{\mathbf{1}}$} & \multicolumn{1}{c}{$\boldsymbol{\pi}_{\mathbf{2}}$} & $\boldsymbol{\pi}_{\mathbf{3}}$ & Total profits \\
\hline$S_{1}=\{A, B, C ; 1,2,3\}$ & 47 & 47 & 47 & 35 & 35 & 35 & 246 \\
$S_{2}=\{A 1, B 2, C 3\}$ & 34 & 34 & 34 & 28.5 & 28.5 & 28.5 & 187.5 \\
$S_{3}=\{C ; A 1, B 2,3\}$ & 42.5 & 42.5 & 21 & 42.5 & 42.5 & 15.5 & 206.5 \\
$S_{4}=\{B, C ; A 1,2,3\}$ & 61.5 & 28 & 28 & 49.5 & 28 & 28 & 222 \\
$S_{5}=\{B C ; A 1,23\}$ & 99 & 21 & 21 & 74.5 & 14 & 14 & 243 \\
$S_{6}=\{B C ; A 1,2,3\}$ & 98 & 31 & 31 & 42.5 & 15.5 & 15.5 & 234.5 \\
$S_{7}=\{B, C ; A 1,23\}$ & 65 & 18.5 & 18.5 & 86 & 24.5 & 24.5 & 237.5 \\
$S_{8}=\{A, B C ; 1,23\}$ & 74 & 37 & 37 & 49.5 & 25 & 25 & 247 \\
$S_{9}=\{A, B C ; 1,2,3\}$ & 83.5 & 41.5 & 41.5 & 28 & 28 & 28 & 250 \\
$S_{10}=\{A, B, C ; 1,23\}$ & 41.5 & 41.5 & 41.5 & 62.5 & 31 & 31 & 250 \\
\hline
\end{tabular}

Proposition 4. In the three-by-three case, $S_{1}$ and $S_{2}$ are stable.

Proof: $S_{1}$ is stable because there is no profitable deviation. There are three possible collective deviations excluding symmetric ones: $B+C, 2+3$, and $A+1 . B+C$ is not profitable since both $B$ and $C$ are worse off in $S_{5} .2+3$ is not profitable since both firms are worse off in $S_{5} . A+1$ is not profitable because both $A$ and 1 are worse off in $S_{2}$.

$S_{2}$ is stable. First, there is no profitable unilateral deviation, as no firm wants to break up with its merger partner. For example, if $C 3$ breaks up, both $C$ and 3 are worse off in $S_{3}$ as compared to $S_{2}$. Second, there is no profitable collective deviation. There are two possible collective deviations: $B+C$ and $2+3 . B+C$ is not profitable since both of them are worse off in $S_{6}$ as compared to $S_{2} .2+3$ is not profitable either since both of them are worse off in $S_{7}$ as compared to $S_{2}$.

$S_{3}$ is not stable since $C+3$ is a profitable deviation. $S_{4}, S_{5}, S_{6}$, and $S_{7}$ are not stable since $B+2$ is a profitable deviation in any of these configurations. $S_{8}, S_{9}$, and $S_{10}$ would have been stable using our stability criterion as specified in the example, but they are unreasonable equilibrium market structures. $B C$ prefers to 
break up in both $S_{8}$ and $S_{9}$, while 23 prefers to break up in $S_{10}$. Those firms won't merge horizontally due to the merger paradox argument (Salant, Switzer, and Reynolds 1983).

Q.E.D.

Acknowledgments: The authors would like to thank Jimmy Chan, Yongmin Chen, Zhiqi Chen, Stephen Ching, Kim Sau Chung, Nicholas Economides, Duozhe Li, Cheng-Zhong Qin, Ning Sun, and the referees for helpful comments and suggestions.

Funding: Financial supports from the Hong Kong General Research Fund (HKU757910H), China National Natural Science Foundation (71273063), China Ministry of Education Humanities and Social Sciences Program (12YJC790236), HKU-Fudan IMBA Joint Research Fund, and the NET Institute are gratefully acknowledged.

\section{References}

Andrade, G., M. Mitchell, and E. Stafford. 2001. "New Evidence and Perspectives on Mergers." Journal of Economic Perspective 15:103-20.

Andrade, G., and E. Stafford. 2004. "Investigating the Economic Role of Mergers." Journal of Corporate Finance 10:1-36.

Bloch, F. 1996. "Sequential Formation of Coalitions in Games with Externalities and Fixed Payoff Division." Games and Economic Behavior 14:90-123.

Bonanno, G., and J. Vickers. 1988. "Vertical Separation." Journal of Industrial Economics 36:257-65.

Colangelo, G. 1995. "Vertical Vs. Horizontal Integration: Pre-Emptive Merging." Journal of Industrial Economics 43:323-37.

Fauli-Oller, R. 2000. "Takeover Waves." Journal of Economics and Management Strategy 9: 189-210.

Fridolfsson, S., and J. Stennek. 2005. "Why Mergers Reduce Profits and Raise Share Prices: A Theory of Preventive Mergers." Journal of the European Economic Association 3:1083-104.

Giovannetti, E. 2005. "Diagonal Mergers and Foreclosure in the Internet." Review of Network Economics 4 (1):33-62.

Greenhut, M., and H. Ohta. 1976. "Related Market Conditions and Interindustrial Mergers." American Economic Review 66:267-77.

Greenhut, M., and H. Ohta. 1979. "Vertical Integration of Successive Oligopolies." American Economic Review 69:137-41.

Hafalir, I. 2008. "Stability of Marriage with Externalities." International Journal of Game Theory 37:353-70.

Harford, J. 2005. "What Drives Merger Waves?" Journal of Financial Economics 77: 529-60. 
Hart, O., and J. Tirole. 1990. "Vertical Integration and Market Foreclosure." Brookings Papers on Economic Activity: Microeconomics 205-76.

Hortacsu, A., and C. Syverson. 2007. "Cementing Relationships: Vertical Integration, Foreclosure, Productivity, and Prices." Journal of Political Economy 115:250-301.

Jensen, M. C. 1993. "The Modern Industrial Revolution and the Challenge to Internal Control Systems.” Journal of Finance 48:831-80.

Jovanovic, B., and P. Rousseau. 2002. "The Q-Theory of Mergers." American Economic Review (Papers and Proceedings) 92:198-204.

Lin, Y. 1988. “Oligopoly and Vertical Integration: A Note." American Economic Review 78:251-4. Lipton, S. 2006. "Merger Waves in the 19th, 20th and 21st Centuries." The Davies Lecture, Osgoode Hall Law School: York University.

Martynova, M., and L. Renneboog. 2008. "A Century of Corporate Takeovers: What Have We Learned and Where Do We Stand?" Journal of Banking and Finance 32:2148-77.

Mitchell, M., and J. Mulherin. 1996. "The Impact of Industry Shocks on Takeover and Restructuring Activity.” Journal Financial Economics 41:193-229.

Nilssen, T., and L. Sorgard. 1998. "Sequential Horizontal Mergers." European Economic Review 42:1683-702.

Ordover, J., G. Saloner, and S. Salop. 1990. “Equilibrium Vertical Foreclosure.” American Economic Review 80:127-42.

Qiu, L., and W. Zhou. 2007. "Merger Waves: A Model of Endogenous Mergers." Rand Journal of Economics 38:214-26.

Ray, D., and R. Vohra. 1999. "A Theory of Endogenous Coalition Structures." Games and Economic Behavior 26:286-336.

Roth, A., and M. Sotomayor. 1990. Two-Sided Matching: A Study in Game-Theoretic Modeling and Analysis. Cambridge: Cambridge University Press.

Rubinstein, A. 1982. "Perfect Equilibrium in a Bargaining Model." Econometrica 50:97-109.

Salant, S., S. Switzer, and R. Reynolds. 1983. "Losses Due To Merger: The Effects of an Exogenous Change in Industry Structure on Cournot-Nash Equilibrium.” Quarterly Journal of Economics 48:185-200.

Salinger, M. 1988. "Vertical Mergers and Market Foreclosure." Quarterly Journal of Economics 103:345-56.

Sasaki, H., and M. Toda. 1996. "Two-Sided Matching Problem with Externalities." Journal of Economic Theory 70:93-106.

Schrader, A., and S. Martin. 1998. "Vertical Market Participation." Review of Industrial Organization 13:321-31.

Shleifer, A., and R. Vishny. 2003. "Stock Market Driven Acquisitions." Journal of Financial Economics 70:295-311.

Toxvaerd, F. 2008. "Strategic Merger Waves: A Theory of Musical Chairs." Journal of Economic Theory 140:1-26.

Vives, X. 1999. Oligopoly Pricing. Cambridge, MA: The MIT Press.

Yao, Z., and W. Zhou, 2011. "Merger Waves in Vertically Related Industries." mimeo.

Ziss, S. 2005. "Horizontal Mergers and Successive Oligopoly." Journal of Industry, Competition and Trade 5:99-114. 